\title{
Trend and correlates of contraceptive use in rural and urban Ethiopia: is there a link to the health extension programme?
}

\author{
Eshetu Gurmu ${ }^{1,2 a}$ and Akim J. Mturi ${ }^{1 *}$ \\ ${ }^{1}$ Research Niche Area 'Population and Health', Faculty of Human and Social Sciences, \\ North-West University (Mafikeng Campus), South Africa. \\ 2 Centre for Population Studies, College of Development Studies, \\ Addis Ababa University, Ethiopia.
}

\begin{abstract}
When international funders shifted funding priorities from family planning to HIV/AIDS in the mid1990s, most family planning programmes in Africa faced serious challenges. The government of Ethiopia took a creative route of establishing the Health Extension Programme (HEP) in 2004 that provides health care services including family planning and integrated population issues into the school curricula besides promulgating contraceptive use as a right for all women of reproductive age. This study aims at analysing the correlates of contraceptive use in rural and urban Ethiopia using the Demographic and Health Survey data of 2000, 2005 and 20I I. Data were analysed using tabular and graphical methods, and a binary logistic regression model was fitted to identify factors associated with contraceptive use. Findings of the study reveal that contraceptive uptake, particularly injectable, has increased markedly in the rural areas as a result of the implementation of the HEP despite regional variations in the level of commitment to the family planning package. Other African countries need to emulate such an initiative, but ensuring equal commitment throughout the nation to overcome any possible outrages.
\end{abstract}

Keywords: Contraceptive use, health extension programme, family planning, rural women, Ethiopia, sub-Saharan Africa

\section{Introduction}

The benefits of using contraception have been widely explained in the literature (Cleland, Bernstein, Ezeh, Faundes, Glasier \& Innis, 2006; Singh, Darroch, Ashford, \& Vlassoff, 2009; Stover \& Ross, 2010; Bongaarts, Cleland, Townsend, Bertrand \& Das Gupta, 20I2). The use of family planning methods helps to improve the health of mothers and children. It contributes towards the reduction of fertility, as well as the reduction of both child and maternal mortality. It also enhances couples' ability to choose the number and timing of births. Wider use of contraceptive practices leads to a decline in higher-parity births and reduces the risk of childbearing at older ages. A study conducted by Singh and colleagues (2009), for instance, reveals that 43 percent of the reduction in maternal deaths in developing countries in 2008 was due to the use of modern contraception. It also has the additional advantage of reducing the mother-to-child transmission of HIV (Hogan, Hogan, Foreman, Naghavi, Ahn, Wang et al., 2010). Cleland and colleagues (2006) argue that promoting effective family planning in countries with high birth rates could avert 32 percent of all maternal deaths and approximately 10 percent of childhood deaths besides reducing poverty and hunger. Simulation models developed by the United Nations Population Division predicted that the increase in contraceptive prevalence rate from about 10 percent to 60 percent in developing countries would reduce fertility by half - from six to about three births per woman (United Nations, 2006).

Large numbers of women in the developing world fail to avoid unwanted and unplanned pregnancies (Bongaarts, 1997). Obstacles to using family planning methods in developing countries, particularly sub-Saharan countries, include a lack of access to information and health care services, opposition from husbands and communities, misperceptions about sideeffects, and cost (Casterline \& Sinding, 2000). Another challenge of family planning programmes (FPP) in developing countries was diminishing funding from donors and policymakers (Bongaarts \& Sinding, 2009). Numerous

a. Correspondence concerning this article: akimmturi@gmail.com 
African countries that placed emphasis on family planning programmes in the 1980s and early 1990s were dependent on external funding. Unfortunately, when international funders shifted their funding priorities to the spread of the HIV/AIDS epidemic (Bongaarts et al., 20I2) from the mid-1990s, most of the FPP's in Africa suffered, since the governments could not manage to create budgets that would maintain the status quo of their programmes. Furthermore, assuming that HIV/AIDS would pose the biggest threat to economic progress and stability on the continent besides causing a health and humanitarian disaster, most of the African leaders have diverted funds, staff, and political energy to combat HIV/AIDS rather than supporting the FPPs (Mayhew \& Adjei 2004). Hence, contraceptive prevalence rates (CPR) estimated in these countries either increased at a very slow pace or became stagnant.

Some of the African countries, nonetheless, reacted differently to the lack of funding for family planning. The Ethiopian government came up with an initiative of integrating population issues into the curricula of secondary schools and higher learning institutes (Ezra and Gebreselassie, 1998), developing a national policy for Ethiopian women that ensures gender equality and equity (Transitional Government of Ethiopia, 1993), setting guidelines for family planning services that allow any woman of reproductive age to use contraceptives without prior consent of her partner/husband (Ministry of Health, 1996), and establishing the Health Extension Programme (HEP) that is aimed to, among other things, increase access of contraceptive use in rural Ethiopia (Ministry of Health, 2007).

The main objectives of this study are to present the trend in the use of contraception in Ethiopia and identify factors associated with contraceptive use over time. The urban and rural areas are compared. The specific objectives are:

- To examine the levels of and trends in contraceptive usage, putting more emphasis on the rural-urban differentials;

- To assess the factors responsible for the change in contraceptive use for both rural and urban areas;

- To find out if there is a link between the use of contraception and introduction of the Health Extension Programme; and

- To explore whether there are best practices in the Ethiopian family planning programme which can be learnt by other African countries.

\section{The family planning programme in Ethiopia}

In Ethiopia, the family planning programme was founded in 1966 when the Family Guidance Association of Ethiopia (FGAE) was established as a local non-government organisation (FGAE, 2000). The programme was expanded widely after the adoption of the National Population Policy of Ethiopia in 1994 and developing a family health programme aimed at improving the well-being of mothers and children in 1995. Prior to that, contraceptive methods were very limited both in type and distribution. Supplies were limited to barrier methods while the clinical methods were restricted to government hospitals and clinics in which husbands' consent and approval were sought (Ministry of Health \& World Health Organization, 1999).

After adopting the National Population Policy of Ethiopia and developing a clearly stated family planning programme following the change of government in 1991, international family planning service-providing and funding organisations such as the Packard Foundation Ethiopia, Marie Stopes International - Ethiopia, the German Development Agency and others have engaged in supporting and implementing the family planning programme of Ethiopia (Ahmed \& Mengistu, 200I). A number of local non-government organisations (NGOs) were also organised under the umbrella of the Ethiopian Consortium of Reproductive Health Associations (CORHRA) - the then Consortium for Family Planning NGOs in Ethiopia (Tawye, Jotie, Shigu, Ngom \& Maggwa, 2005). To expand and improve the services, a community-based distribution (CBD) programme was later introduced by local as well as international NGOs with the material and financial support of donors and development partners (Ahmed \& Mengistu, 2002). The CBD, though it introduced contraceptive pills and condoms to the rural communities and helped the poor access and overcome the unmet need for contraception, had a fundamental weakness in not being sustainable (Giday, Asnake \& Wilder, 2008). Given the vol- 
untary service and/or functioning on a specified commission rate, family planning clients have been suffering from interruption of the service when the providers left to pursue better opportunities or ceased to operate.

Unlike the CBD programme, the HEP involves recruiting health extension workers (HEWs) who are trained for a year on 16 packages (family planning being one of them) and are then deployed to the communities to provide primary and preventive health care services (Argaw, 2007). The HEP is more sustainable, as HEWs are full-time salaried employees. The HEWs are purposely recruited from the same or nearby communities to reduce barriers to communication between service providers and beneficiaries of the programme. In addition, the programme is supported by voluntarily community health agents (VCHA) and model families to ensure the acceptability of family planning services (CNHDE, 20I Ib). Each of the HEWs organises and trains I0-I5 volunteers to support them in mobilising members of their communities and adopt the HEP. VCHAs are key roleplayers in dealing with complex topics such as sexuality in societies with conservative cultures by making door-to-door visits to explain family planning methods, distribute condoms and pills and make referrals for clinical family planning methods (Giday et al., 2008). HEWs are also working with model households; that is, capable families who can quickly adopt healthy behaviour patterns that set a positive example for their neighbours. Households identified as model units are given training for 96 hours, graduate by receiving certificates recognising them as model families if they implement 75 percent of the programme activities, and if there are non-pregnant sexually active women of reproductive age that do not wish to have a baby soon. A model household is selected for every five households, and is intended to influence, coordinate, give advice and generate opinions in their living environs (Ministry of Health, 2010).

Following the major activities of the population in each of the regions, three sets of HEPs were developed, namely agrarian-HEP, pastoralist-HEP and urban-HEP (Ministry of Health, 20I0). The Agrarian-HEP, the first of the three sets, was launched in 2004. It concentrated in four regions \{Oromia, Amhara, Southern
Nations Nationalities and Peoples (SNNP) and Tigray\} which constitute about 86.3 percent of the total population in the country (Population Census Commission, 2008). The pastoralistHEP was established for four regions (Benishangul Gumuz, Gambela, Somali and Afar) which are pastoralist and semi-pastoralist regions and located in the peripheries. Even though the pastoralist-HEP was launched in 2007, it has not yet been fully implemented due to the nomadic lifestyle of people residing in those regions (CNHDE, 20lla). The urbanHEP was established for the Addis Ababa, Harari and Dire Dawa regions. The launch of urban-HEP took place in 20I I. The HEP, in general, has an overarching strategy for family planning services that offer clients easy access and a wide range of affordable contraceptive methods through public-sector health systems that operate with funding partnerships. It is also expected to provide the services to the hard-to-reach communities.

The extensive family planning programme in Ethiopia is financed by the Ethiopian Government and partner organisations. As indicated in the Health Sector Development Plan 2010/1I $2014 / 15$, a third of the budget made available for implementation of the programme including family planning services was allocated by the Ethiopian Government (Ministry of Health, 2010). According to the speech delivered by the Ethiopian Minister of Health to the delegates of the 2012 London Summit on Family Planning, the Ethiopian family planning programme has a 50 percent funding gap for commodities despite government's increasing budgetary allocations to family planning and donors' contributions (All Africa, 20I2). To overcome such challenges, the Ethiopian Government has developed a five point action plan aimed at (a) making family planning a cross-sectoral development issue by securing family planning commitments across all stakeholders and all leadership levels, (b) making more domestic funding available for family planning, (c) focusing more efforts on adolescent girls by expanding youth-friendly services, (d) scaling-up delivery of services to hard-to-reach groups, and (e) monitoring the availability of contraceptives by using innovative approaches (All Africa, 20I2). 


\section{Data and methods}

The analysis uses the Ethiopian Demographic and Health Surveys (EDHS) conducted in 2000, 2005 and 201 I. These three data sets are comparable. The 2000 EDHS was conducted before the launch of Agrarian-HEP, the 2005 EDHS was conducted a year after the launch, and the most recent EDHS was conducted seven years after the launch. A total of 8596,8102 and 8445 currently married non-pregnant women of reproductive age (i.e. 15-49 years) living in rural areas respectively in 2000, 2005 and 20II were included in the study while the sample sizes for urban areas were 1193, 959 and 1844 (see Table I). The model was fitted only to currently married and non-pregnant women. Amenorrheic and/or breastfeeding women are grouped together as using what is referred to as the lactational amenorrhea method (LAM).

Distributions of respondents by variables included in the analysis are given in Table I. These include socio-economic and demographic variables such as age of women, region of residence, women's education, religion, work status and access to media (i.e. radio, television and newspaper), number of living children, child loss experience, desire for more children, husband's education and occupation as well as household wealth status. All variables were used as provided in the data sets except two, namely household wealth and region of residence. The wealth index variable available in the Ethiopian DHS data was not used due to the fact that it fails to reflect the prevailing situation of economic status of respondents in urban and rural areas in Ethiopia. So another composite variable (household wealth) was created differently for rural and urban areas. In rural areas, it was based on possession of number of animals, agricultural land size, roof material, use of kerosene pressure lamp, table and chair whilst in urban areas it was use of electricity, telephone, refrigerator, type of toilet facility, and types of floor materials. The weights used for each of these variables in creating the composite variable were generated using the principal components analysis. The categories of the household wealth variable were classified into low, medium and high taking the first, second and third triciles of each of the rural and urban indices as cutting points. The variable region has six categories namely Tigray, Amhara, Oromia, SNNP, Addis Ababa and other (including Gambella, Benishangual Gumuz, Afar, Somali, Harari, and Dire Dawa). Both tabular and graphical analyses are used in the bivariate analysis. The multivariate analysis employed is binary logistic regression since the dependent variable (current use of contraception) has only two outcomes. Analyses are conducted for rural and urban areas separately.

As it is with any secondary data analysis, this study has its own limitations. The DHS data sets do not provide an opportunity to assess the effects of some of underlying structural factors such as population pressure, food insecurity, urbanization, migration, and quality of health and education services on contraceptive uptake. It should be noted however that some variables selected for this study measure these factors indirectly.

Table I Distribution of variables used in the multivariate analysis for currently married women by place of residence in Ethiopia: 2000, 2005 and 20II

\begin{tabular}{|c|c|c|c|c|c|c|}
\hline \multirow[t]{2}{*}{ Variable } & \multicolumn{2}{|l|}{2000} & \multicolumn{2}{|l|}{2005} & \multicolumn{2}{|l|}{2011} \\
\hline & Rural & Urban & Rural & Urban & Rural & Urban \\
\hline \multicolumn{7}{|l|}{ Age } \\
\hline $15-19$ & 782 & 80 & 667 & 43 & 678 & 87 \\
\hline $20-24$ & 1602 & 204 & 1400 & 173 & 1412 & 350 \\
\hline $25-29$ & 1756 & 294 & 1849 & 216 & 2007 & 504 \\
\hline $30-34$ & 1370 & 202 & 1380 & 170 & 1376 & 344 \\
\hline $35-39$ & 1226 & 215 & 1209 & 133 & 1309 & 282 \\
\hline $40-44$ & 983 & 113 & 839 & 121 & 863 & 169 \\
\hline $45-49$ & 876 & 84 & 758 & 104 & 799 & 107 \\
\hline \multicolumn{7}{|c|}{ Region of residence } \\
\hline Tigray & 499 & 127 & 490 & 81 & 500 & 120 \\
\hline Amhara & 2408 & 179 & 2177 & 152 & 2300 & 476 \\
\hline
\end{tabular}




\begin{tabular}{|c|c|c|c|c|c|c|}
\hline Oromia & 3366 & 403 & 2998 & 302 & 3463 & 500 \\
\hline SNNP & 1986 & 147 & 1892 & 97 & 1798 & 224 \\
\hline Addis Ababa & --- & 236 & --- & 219 & --- & 341 \\
\hline Other & 337 & 101 & 546 & 108 & 385 & 182 \\
\hline \multicolumn{7}{|l|}{ Women's education } \\
\hline No education & 7602 & 519 & 6792 & 298 & 6147 & 588 \\
\hline Primary & 868 & 294 & 1185 & 217 & 2156 & 706 \\
\hline Secondary+ & 126 & 380 & 126 & 444 & 142 & 549 \\
\hline \multicolumn{7}{|l|}{ Religion } \\
\hline Orthodox & 4087 & 772 & 3448 & 679 & 3362 & 1128 \\
\hline Protestant & 1443 & 126 & 1590 & III & 2017 & 302 \\
\hline Muslim & 2634 & 284 & 2748 & 154 & 2794 & 392 \\
\hline Others & 433 & 10 & 315 & 15 & 178 & 18 \\
\hline \multicolumn{7}{|l|}{ Women's work status } \\
\hline Not working & 3096 & 498 & 5667 & 545 & 3662 & 800 \\
\hline Working for family & 2711 & $13 \mid$ & 1673 & 196 & 2319 & 164 \\
\hline Employed elsewhere & 2786 & 561 & 759 & 218 & 2448 & 878 \\
\hline \multicolumn{7}{|l|}{ Household wealth } \\
\hline Low & 2369 & 382 & 2319 & 480 & 3016 & 736 \\
\hline Medium & 3215 & 459 & 2618 & 243 & 2783 & 482 \\
\hline High & 2990 & 351 & 2580 & 231 & 2627 & 620 \\
\hline \multicolumn{7}{|c|}{ Age differences of husband and wife } \\
\hline 5 years & 2017 & 357 & 2148 & 299 & 2691 & 610 \\
\hline $5-9$ years & 3265 & 420 & 3075 & 341 & 3249 & 662 \\
\hline $10+$ years & 3301 & 406 & 2836 & 315 & 2464 & 569 \\
\hline \multicolumn{7}{|c|}{ Number of living children } \\
\hline None & 912 & 179 & 678 & 122 & 748 & 270 \\
\hline 1_2 & 2718 & 448 & 2246 & 380 & 2379 & 814 \\
\hline 344 & 2330 & 293 & 2383 & 247 & 2342 & 467 \\
\hline $5+$ & 2636 & 273 & 2795 & 211 & 2975 & 292 \\
\hline \multicolumn{7}{|l|}{ Child loss experience } \\
\hline No & 4396 & 804 & 4793 & 733 & 5170 & 1499 \\
\hline Yes & 4200 & 389 & 3310 & 226 & 3275 & 344 \\
\hline \multicolumn{7}{|c|}{ Desire for more children } \\
\hline Want soon & 1951 & 236 & 1300 & 163 & 1370 & 364 \\
\hline Want later & 3756 & 436 & 3275 & 316 & 3771 & 763 \\
\hline Do not want & 2639 & 464 & 3350 & 446 & 3100 & 656 \\
\hline \multicolumn{7}{|l|}{ Access to media } \\
\hline Not at all & 6743 & 248 & 5333 & 153 & 3626 & 186 \\
\hline Sometimes & $135 \mid$ & 417 & 1931 & 296 & $313 \mid$ & 561 \\
\hline Frequently & 495 & 527 & 815 & 507 & 1677 & 1096 \\
\hline \multicolumn{7}{|l|}{ Husband's education } \\
\hline No education & 6071 & 334 & 5200 & 176 & 4680 & 343 \\
\hline Primary & 1984 & 277 & 2301 & 220 & 3298 & 764 \\
\hline Secondary+ & 502 & 571 & 559 & 560 & 391 & 727 \\
\hline \multicolumn{7}{|l|}{ Husband's occupation } \\
\hline Agriculture & 7896 & 122 & 7501 & 74 & 7455 & 234 \\
\hline Non-agriculture & 695 & 1064 & 589 & 869 & 937 & 1600 \\
\hline Total & 8596 & 1193 & 8102 & 959 & 8445 & 1844 \\
\hline
\end{tabular}

Source: Computed from EDHS 2000, 2005 and 20I I data sets. Note: --- not applicable. 


\section{Results}

Bivariate analysis

Figure 1: The trend in CPR for rural and urban areas of Ethiopia: 1990-2011

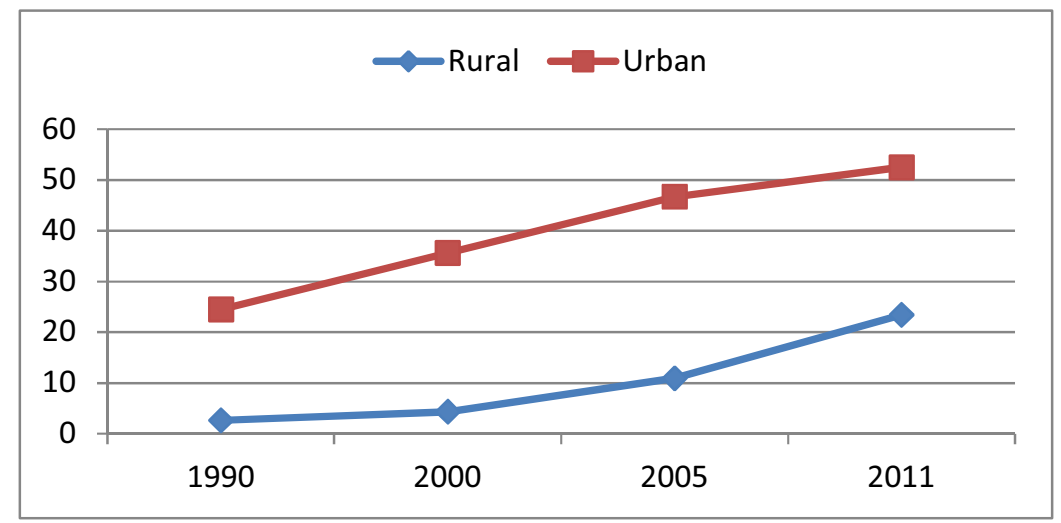

Source: CSA (1993); CSA and ORC Macro (2001); CSA and ORC Macro (2006); CSA and ICF International (2012)

Only 4.8 percent of the currently married women of childbearing age were using a contraceptive method in Ethiopia in 1990 which increased to 8.1 percent in 2000. There was also a modest increase to 14.7 percent in 2005. However, a sharp increase was registered during the period 2005-20II to a CPR of 28.6 percent in 201 I. As shown in Figure 2, whilst urban dwellers maintained the same rising trend observed since 1990, the curve for rural women is steep during the period $2005-201 \mathrm{I}$. That is, a
CPR changes from 10.9 to 23.4 percent.

Figure 2 shows that injectable is the most popular contraceptive method in both rural and urban areas. In this context, injectable began to be provided by HEWs during the implementation of Agrarian-HEP. Other contraceptive methods are used by a small proportion of women. In rural Ethiopia, access to health facilities and family planning services track each other closely (Pörtner, Beegle \& Christiaensen, 20II). 
Figure 2: Trend in contraceptive method mix among currently married women residing in rural and urban Ethiopia: 2000, 2005 and 2011

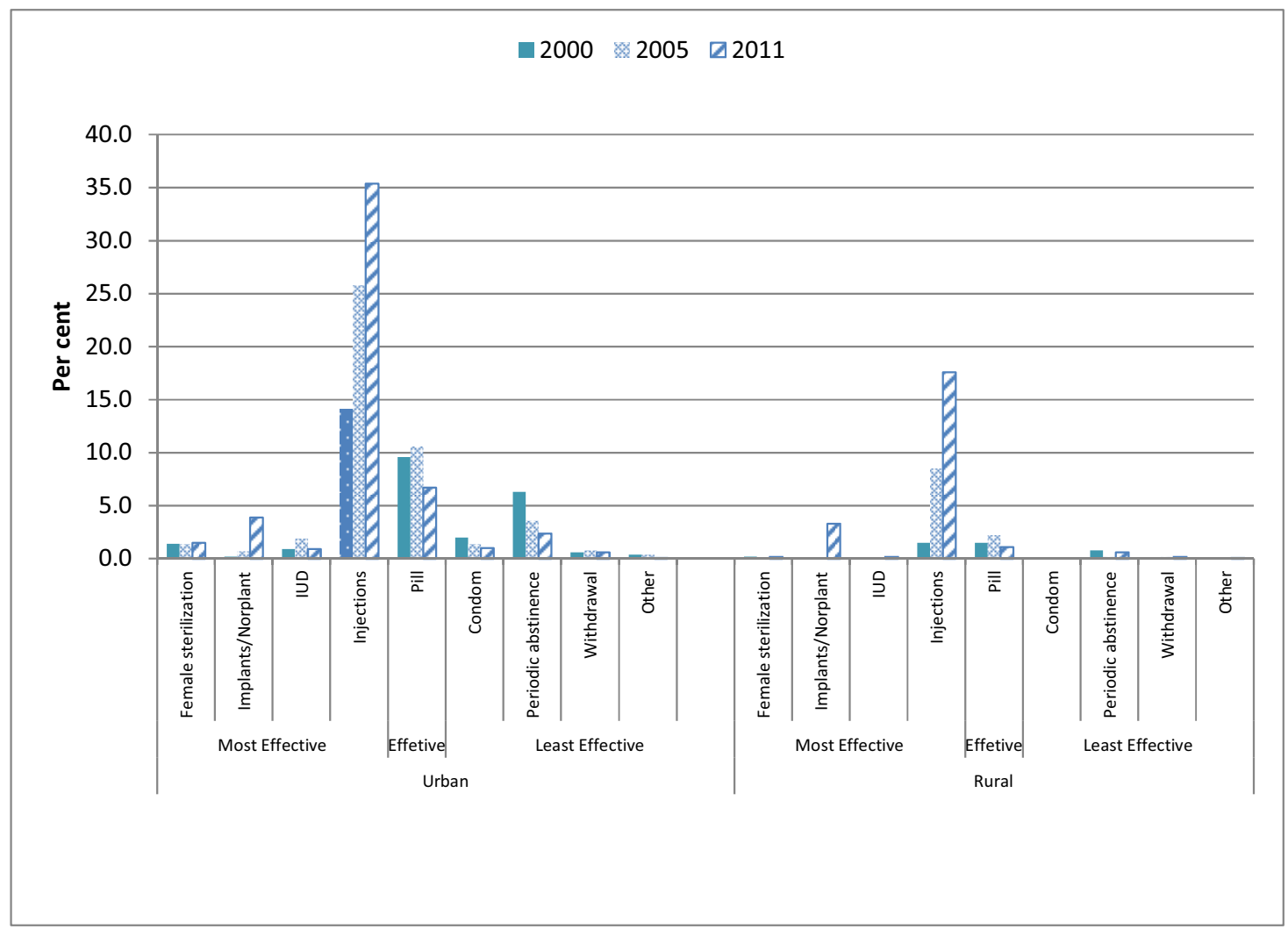

Source: Same as Table 1

The regional differentials of contraceptive prevalence rates are presented in Table 2. As expected, urban women use contraception to a higher degree than rural women in all the regions. Use of contraception among rural women living in the three of the four regions in which the Agrarian-HEP was implemented has doubled during the period 2005-20II, but the rate of increase was modest in Tigray. Use of contraception for rural women in the 'other' regions, in which the majority are pastoralists, has not also improved significantly over time.
For example, in $201 \mathrm{I}$, only 9 percent of rural women in the 'other' regions were using contraception compared to their counterparts whose proportions ranged from 19 to 30 percent. Similarly, although an increase in contraceptive prevalence rate was observed in urban Ethiopia, where Addis Ababa is playing a leading role, a lower contraceptive uptake was observed in urban areas of the 'other' regions as contraceptive prevalence rate has declined from 32.4 percent in 2005 to 29.7 percent in $201 \mathrm{I}$.

Table 2 Distribution of contraceptive prevalence rates by background characteristics, Ethiopia: 2000, 2005 and $201 \mathrm{I}$

\begin{tabular}{lllllll}
\hline Variable & Rural & \multicolumn{5}{c}{ Urban } \\
\cline { 2 - 7 } & 2000 & 2005 & $20 I I$ & 2000 & 2005 & $20 I I$ \\
\hline Age & & & & & & \\
I5-24 & 2.7 & 10.5 & 25.6 & 36.3 & 50.5 & 60.0 \\
$25-34$ & 5.2 & 11.3 & 24.4 & 35.3 & 53.1 & 58.4 \\
$35-49$ & 4.4 & 10.8 & 20.8 & 35.4 & 37.5 & 37.6 \\
Region of residence & & & & & & \\
Tigray & 5.2 & 12.1 & 16.8 & 29.7 & 43.2 & 45.0 \\
Amhara & 5.3 & 14.1 & 29.9 & 36.9 & 44.4 & 53.4
\end{tabular}




\begin{tabular}{|c|c|c|c|c|c|c|}
\hline Oromia & 3.5 & 10.3 & 21.9 & 32.9 & 47.0 & 56.4 \\
\hline SNNP & 4.1 & 10.3 & 22.9 & 37.4 & 43.3 & 49.6 \\
\hline Addis Ababa & --- & ---- & --- & 45.1 & 57.5 & 62.5 \\
\hline Other & 4.5 & 3.3 & 9.4 & 26.7 & 32.4 & 29.7 \\
\hline \multicolumn{7}{|l|}{ Women's education } \\
\hline No education & 3.3 & 9.0 & 19.9 & 23.7 & 32.4 & 45.8 \\
\hline Primary & 9.8 & 19.3 & 30.8 & 35.8 & 45.6 & 50.6 \\
\hline Secondary+ & 24.4 & 38.1 & 62.7 & 51.6 & 56.8 & 62.0 \\
\hline \multicolumn{7}{|l|}{ Religion } \\
\hline Orthodox & 4.7 & 13.8 & 28.4 & 38.2 & 49.6 & 54.8 \\
\hline Protestant & 3.7 & 10.7 & 25.4 & 35.4 & 48.2 & 59.6 \\
\hline Muslim & 3.9 & 7.9 & 16.6 & 29.6 & 31.8 & 41.6 \\
\hline Other & 4.6 & 7.3 & 19.7 & 10.0 & 50.0 & 29.4 \\
\hline \multicolumn{7}{|l|}{ Women's work status } \\
\hline Not working & 2.7 & 9.1 & 19.0 & 35.7 & 45.5 & 52.3 \\
\hline Working for family & 4.6 & 14.5 & 27.0 & 31.3 & 41.6 & 40.9 \\
\hline Employed elsewhere & 5.6 & 16.4 & 26.6 & 36.5 & 54.1 & 54.9 \\
\hline \multicolumn{7}{|l|}{ Household wealth } \\
\hline Low & 3.0 & 7.2 & 19.0 & 21.7 & 38.5 & 45.6 \\
\hline Medium & 3.9 & 9.7 & 25.7 & 39.2 & 58.0 & 57.7 \\
\hline High & 5.7 & 14.7 & 26.0 & 46.2 & 51.3 & 56.5 \\
\hline \multicolumn{7}{|c|}{ Age differences of husband and wife } \\
\hline 5 years & 4.3 & 12.2 & 25.2 & 36.4 & 47.7 & 55.7 \\
\hline $5-9$ years & 4.6 & 11.2 & 25.0 & 39.2 & 51.3 & 52.5 \\
\hline $10+$ years & 3.9 & 9.8 & 19.2 & 31.0 & 40.8 & 49.0 \\
\hline \multicolumn{7}{|c|}{ Number of living children } \\
\hline None & 1.6 & 5.3 & 17.5 & 18.3 & 27.9 & 40.0 \\
\hline I_2 & 3.2 & 10.4 & 26.4 & 33.0 & 53.8 & 61.2 \\
\hline 344 & 5.0 & 11.0 & 24.5 & 42.7 & 52.2 & 56.1 \\
\hline $5+$ & 5.7 & 12.7 & 21.6 & 43.6 & 37.9 & 33.9 \\
\hline \multicolumn{7}{|l|}{ Child loss experience } \\
\hline No & 4.3 & 11.8 & 27.1 & 37.9 & 51.8 & 57.0 \\
\hline Yes & 4.2 & 9.7 & 17.6 & 30.8 & 30.1 & 32.8 \\
\hline \multicolumn{7}{|c|}{ Desire for more children } \\
\hline Want soon & 2.1 & 4.8 & 17.4 & 14.9 & 20.9 & 31.0 \\
\hline Want later & 3.1 & 9.9 & 23.4 & 39.5 & 60.1 & 60.3 \\
\hline Do not want & 7.3 & 14.7 & 27.3 & 43.1 & 47.1 & 55.3 \\
\hline \multicolumn{7}{|l|}{ Access to media } \\
\hline Not at all & 3.5 & 8.4 & 19.6 & 20.2 & 25.3 & 23.7 \\
\hline Sometimes & 6.0 & 13.7 & 23.5 & 38.4 & 44.8 & 54.9 \\
\hline Frequently & 9.3 & 21.1 & 31.7 & 40.8 & 54.6 & 56.1 \\
\hline \multicolumn{7}{|l|}{ Husband's education } \\
\hline No education & 3.6 & 8.1 & 19.7 & 18.9 & 29.5 & 44.9 \\
\hline Primary & 4.7 & 14.0 & 26.3 & 31.0 & 44.7 & 50.7 \\
\hline Secondary+ & 10.8 & 24.0 & 41.9 & 48.1 & 53.0 & 58.3 \\
\hline \multicolumn{7}{|l|}{ Husband's occupation } \\
\hline Agriculture & 3.8 & 10.2 & 21.8 & 22.1 & 10.8 & 42.5 \\
\hline Non-agriculture & 9.1 & 20.5 & 36.5 & 37.0 & 49.5 & 53.9 \\
\hline Total & 4.3 & 10.9 & 23.4 & 35.6 & 46.7 & 52.5 \\
\hline
\end{tabular}


Table 2 also presents the distribution of CPR by other background variables. It should be noted that CPR of women with at least secondary education who were using contraception was the same in 20I I regardless of whether they lived in rural or urban areas. However, in all other variables, urban women use contraceptives more than rural women. In general terms, the period 2005-20 II is doing better than 2000-2005. It can be observed from the table that there are categories of urban women which have decreased (i.e. CPR has declined) during the period 2005-20II. These include women residing in the 'other' regions, women in the 'other' religious group, women who have medium household wealth, women who have at least 5 living children and women who do not have access to media. It can be concluded that contrary to rural women whose contraceptive uptake is particularly convincing during the period 2005-20II, the trend of CPR for urban women has slowed down during the same period because some categories of women were not using contraception to the same extent in $201 \mathrm{I}$ as they did in 2005.

\section{Multivariate analysis}

Thirteen variables were identified to be associated with current use of contraception in Ethiopia (details are provided in Table I). A parsimonious logistic regression model is fitted for each of the three data sets. As stated earlier, these models are fitted separately for rural and urban women. Results of the multivariate analysis suggest that region of residence was not significant in 2000 in both rural and urban areas, but was significant in 2005 and 20I I, after controlling for other variables (see Table 3). In 2005 , only women who were residing in the urban centres of Oromia and Addis Ababa were more likely to use contraception than those living in Tigray urban centres. For their rural counterparts, all regions except Amhara were less likely to use contraception than Tigray. In 201 I, urban women of Amhara joined those of Oromia and Addis Ababa to be more likely to use contraception than those of Tigray. The results for rural areas have changed significantly in 2011. Rural women in Amhara, Oromia and SNNP were more likely to use contraceptives than those of rural Tigray and those in the 'other' regions were no longer significantly different to Tigray. In other words, controlling for other intervening variables women residing in rural areas of Amhara, Oromia and SNNP improved their contraceptive usage significantly during the period 2005-20 I I whilst those residing in 'other' regions were found to have the same level of improvement observed in Tigray. The little improvement in contraceptive use in Tigray despite being a component of the Agrarian HEP needs further investigation whilst the situation in pastoralist areas could be attributed to the unfavourable atmosphere for providing the service as widely as expected.

Table 3 The odd ratios of the parsimonious logistic model on the factors associated with current contraceptive use among currently married women of Ethiopia by place of residence: 2000, 2005 and 201 I

\begin{tabular}{|c|c|c|c|c|c|c|}
\hline \multirow[t]{2}{*}{ Variable } & \multicolumn{2}{|l|}{2000} & \multicolumn{2}{|l|}{2005} & \multicolumn{2}{|l|}{2011} \\
\hline & Rural & Urban & Rural & Urban & Rural & Urban \\
\hline Age & ns & $1.22 *(0.08)$ & ns & I.37I***(0.09) & I.II***(0.03) & $1.10(0.06)$ \\
\hline Age squared & ns & $0.99 * *(0.00)$ & ns & $0.994 * *(0.00)$ & $0.99 * *(0.00)$ & $0.99 * *(0.00)$ \\
\hline \multicolumn{7}{|c|}{ Region of Residence } \\
\hline Tigray & ns & Ns & $\mathrm{RC}$ & $\mathrm{RC}$ & $\mathrm{RC}$ & $\mathrm{RC}$ \\
\hline Amhara & ns & Ns & I.II (0.17) & I.34 (0.33) & $2.88 * *(0.14)$ & $2.12 * *(0.23)$ \\
\hline Oromia & ns & Ns & $0.59 * *(0.17)$ & $1.96 *(0.31)$ & $1.66 * *(0.14)$ & $1.66 *(0.23)$ \\
\hline SNNP & ns & Ns & $0.61 * *(0.18)$ & $1.13(0.37)$ & $1.69 * *(0.16)$ & $1.16(0.27)$ \\
\hline Addis Ababa & - & Ns & - & $2.05 *(0.32)$ & - & $2.12 * *(0.23)$ \\
\hline Other & ns & Ns & $0.33^{* *}(0.32)$ & $\mathrm{I} .07(0.38)$ & $0.99(0.24)$ & $0.76(0.27)$ \\
\hline \multicolumn{7}{|c|}{ Women's educational level } \\
\hline No education & $\mathrm{RC}$ & $\mathrm{RC}$ & $\mathrm{RC}$ & ns & $\mathrm{RC}$ & ns \\
\hline Primary & $2.76 * *(0.15)$ & $1.28(0.19)$ & I.73***(0.10) & ns & I.52**(0.07) & ns \\
\hline Secondary + & $6.96 * *(0.26)$ & I. .8 I**(0.20) & $2.6 I^{* *}(0.25)$ & ns & $3.81 * *(0.23)$ & ns \\
\hline
\end{tabular}




\begin{tabular}{|c|c|c|c|c|c|c|}
\hline \multicolumn{7}{|l|}{ Religion } \\
\hline Orthodox & ns & $\mathrm{RC}$ & ns & ns & $\mathrm{RC}$ & $\mathrm{RC}$ \\
\hline Protestant & ns & $0.63 *(0.22)$ & ns & ns & $0.96(0.09)$ & I.53* $(0.17)$ \\
\hline Muslim & ns & $0.85(0.19)$ & ns & ns & $0.65 * *(0.08)$ & $0.66 * *(0.14)$ \\
\hline Others & ns & $0.21(1.06)$ & ns & ns & $0.75(0.22)$ & $0.59(0.55)$ \\
\hline \multicolumn{7}{|l|}{ Women's work status } \\
\hline Not working & $\mathrm{RC}$ & Ns & $\mathrm{RC}$ & $\mathrm{RC}$ & $\mathrm{RC}$ & ns \\
\hline Working for family & I.63**(0.15) & Ns & I.68**(0.09) & $0.86(0.20)$ & I.5I***(0.07) & ns \\
\hline Employed elsewhere & $1.20 * *(0.14)$ & Ns & $1.82 * *(0.12)$ & $1.86 * *(0.20)$ & $1.30 * *(0.07)$ & ns \\
\hline \multicolumn{7}{|l|}{ Household wealth } \\
\hline Low & RC & $\mathrm{RC}$ & RC & $\mathrm{RC}$ & $\mathrm{RC}$ & $\mathrm{RC}$ \\
\hline Medium & $1.18(0.16)$ & I.68**(0.18) & $1.3 \mathrm{I} *(0.1 \mathrm{I})$ & $1.85^{* *}(0.20)$ & I. $4 \mathrm{I}^{* *}(0.07)$ & $1.63 * *(0.14)$ \\
\hline High & $1.43 *(0.16)$ & $2.07 * *(0.20)$ & $1.67 * *(0.1 \mathrm{I})$ & $1.34(0.23)$ & I. $35^{* *}(0.07)$ & I. $50 * *(0.15)$ \\
\hline \multicolumn{7}{|c|}{ Number of living children } \\
\hline None & $\mathrm{RC}$ & $\mathrm{RC}$ & $\mathrm{RC}$ & $\mathrm{RC}$ & $\mathrm{RC}$ & $\mathrm{RC}$ \\
\hline $1-2$ & I.64 (0.30) & I.63* $(0.25)$ & $2.05 * *(0.22)$ & $2.38 * *(0.28)$ & I.89**(0.12) & $3.11 * *(0.16)$ \\
\hline $3-4$ & $2.79 * *(0.34)$ & $3.34 * *(0.30)$ & $2.24 * *(0.25)$ & $3.44 * *(0.35)$ & $1.84 * *(0.15)$ & $3.94 * *(0.20)$ \\
\hline $5+$ & $3.53 * *(0.36)$ & $5.89 * *(0.35)$ & $2.90 * *(0.27)$ & $4.13^{* *}(0.40)$ & $1.63^{* *}(0.16)$ & $3.76 * *(0.25)$ \\
\hline \multicolumn{7}{|l|}{ Desire for more children } \\
\hline Want Soon & $\mathrm{RC}$ & $\mathrm{RC}$ & $\mathrm{RC}$ & $\mathrm{RC}$ & $\mathrm{RC}$ & ns \\
\hline Want later & $1.17(0.19)$ & $3.06 * *(0.23)$ & $1.60 * *(0.16)$ & $4.55 * *(0.26)$ & $1.16(0.09)$ & ns \\
\hline Do not want & $2.92 * *(0.19)$ & $2.64 * *(0.24)$ & $2.79 * *(0.16)$ & $4.36 * *(0.27)$ & $1.78 * *(0.10)$ & ns \\
\hline \multicolumn{7}{|l|}{ Access to media } \\
\hline Not at all & ns & Ns & RC & $\mathrm{RC}$ & $\mathrm{RC}$ & $\mathrm{RC}$ \\
\hline Sometimes & ns & Ns & $1.24 *(0.09)$ & $1.56(0.26)$ & I.I3* (0.07) & $3.60 * *(0.21)$ \\
\hline Frequently & ns & Ns & I.68**(0.12) & $2.23 * *(0.26)$ & I.36**(0.08) & $3.02 * *(0.20)$ \\
\hline $\begin{array}{l}\text { Husband's education } \\
\text { No Education }\end{array}$ & ns & Ns & RC & ns & $\mathrm{RC}$ & ns \\
\hline Primary & ns & Ns & I.44**(0.10) & ns & I.19**(0.06) & ns \\
\hline Secondary + & ns & Ns & $1.83 * *(0.15)$ & ns & $1.20(0.14)$ & ns \\
\hline \multicolumn{7}{|l|}{ Child loss experience } \\
\hline No & ns & Ns & ns & ns & $\mathrm{RC}$ & $\mathrm{RC}$ \\
\hline Yes & ns & Ns & ns & ns & $0.65 * *(0.07)$ & $0.62 * *(0.15)$ \\
\hline \multicolumn{7}{|l|}{ Husband's occupation } \\
\hline Agriculture & $\mathrm{RC}$ & Ns & $\mathrm{RC}$ & $\mathrm{RC}$ & $\mathrm{RC}$ & ns \\
\hline Non-agriculture & $1.62 * *(0.17)$ & Ns & $1.41 *(0.15)$ & $5.90 * *(I .4 I)$ & $1.67 * *(0.09)$ & ns \\
\hline Constant & $0.00 * *(0.94)$ & $0.00 * *(1.21)$ & $0.01 * *(0.68)$ & $0.00 * *(1.47)$ & $0.01 * *(0.47)$ & $0.06 * *(0.89)$ \\
\hline
\end{tabular}

Source: Same as Table I

Note: *P $<0.05$; $* * \mathrm{P}<0.01$; ns $=$ not significant; standard errors are in parentheses;

$\mathrm{RC}=$ reference category; -- not applicable

There was a strong and positive relationship between household wealth and use of contraception both in urban and rural areas. Women belonging to medium and high level wealthy households were more likely to use contraceptives than women in low-income households. The results show that rural women with primary and secondary education use contraception more than their counterparts with no education in all of the survey years. In contrast, no statistically significant difference in contraceptive use by educational level is observed among women living in urban Ethiopia except in 2000. The effect of education on contraceptive use in urban Ethiopia is diminished in 2005 and $20 \mathrm{II}$ indicating that once access to contraceptive use is ensured and the impact of traditional norms and values are eroded, a woman can use 
modern contraceptives to regulate fertility irrespective of her educational attainment. Variation in contraceptive use by husband's educational attainment is also limited to rural Ethiopia, indicating that the support for partners is required only in areas where traditions are perpetuating large family sizes.

Statistically significant variations in contraceptive use are also found by work status mainly in rural Ethiopia. Significant variations in using contraceptives in urban Ethiopia were observed only in 2005 among women employed by someone else. This indicates that the impact of exposure to the external world to adopt contraceptives may not necessarily be preferred in societies where contraceptive supplies are widely available and women could get adequate information from different sources including media, social clubs and similar places. Higher likelihood of contraceptive use among working women in rural areas could be the effect of social networking at work places, and exchanges of ideas with colleagues, and other persons with whom they interact whilst accomplishing their daily tasks (Alvergne, Gibson, Gurmu \& Mace, 20II). Following the same trend, higher likelihood of contraceptive use by partner's occupation is observed in rural areas in all the study periods with the exception of a statistically significant effect in urban Ethiopia in 2005. According to the results, husbands engaged in non-agricultural work in rural Ethiopia are more supportive of their wives using contraceptives than their counterparts who are engaged in agricultural work. The variation could be attributed to the demand for additional labour in agricultural work.

A statistically significant positive relationship between contraceptive use and number of living children is observed both in rural and urban Ethiopia in all the survey years. The likelihood of contraceptive use was the highest among women with five or more children both in rural and urban areas in 2000 although the variation in contraceptive use by the number of living children has been reduced over time, but maintaining the statistically significant effect.

The relationship between the desire for more children and contraceptive use has been diminished in urban Ethiopia in 2011 while its particular effect was observed among rural women who do not want any more children.
In addition, child loss experience is observed to affect the use of contraceptives in Ethiopia only in 201I, when family planning services were much more widespread than in other years. It has been observed to have the potential of reducing contraceptive use by approximately 35 percent both in rural and urban Ethiopia. Similarly, the role of media in promoting contraceptive use in rural Ethiopia is noted after the implementation of agrarian-HEP. Rural women having both occasional and frequent access to the media are observed respectively using contraceptives at least by 13 and 36 percent more likely than those who do not have access at all. In urban areas, significant variations in contraceptive use by level of access to media were observed among those who had frequent access to the media in 2005 and 20I I. The statistically significant effect of those having occasional access to the media was also observed in $201 \mathrm{I}$, indicating that media is exerting an influence on contraceptive use in more recent years, coinciding with implementation of the Agrarian-HEP.

Religion appeared to have no effect on contraceptive use in the past but a degree of impact was noted in the recent past. Followers of the Protestant religion, which had been 37 percent less likely to use contraceptives in 2000 in urban Ethiopia, were found to increase their chance of using contraceptives by 53 percent in 2011 , when compared to followers of Orthodox Church. Muslims were less likely to using contraceptives than Orthodox in $201 \mathrm{I}$ both in rural and urban areas. The only variable that was not found to be significant in all data sets is the age difference between the wife and her husband.

\section{Discussions}

\section{Implementation of HEP and regional variation in contraceptive use provide conflicting results}

If the trend in contraceptive use is to be associated with the implementation of Agrarian-HEP, then the four regions (Oromia, Tigray, SNNP, and Amhara) need to have similarities, especially in rural areas. The results show that Tigray stands separately from the other three regions. Whilst there is a consistent improvement in use of contraception during the period 2005-20 I I in rural Amhara, Oromia and SNNP, rural Tigray did not follow the same trend. In fact, the multi- 
variate analysis showed that Tigray is significantly different to those three regions in $20 \mathrm{l} \mathrm{l}$. It can be concluded that there is a link between implementation of Agrarian-HEP and rise in use of contraception at least in Amhara, Oromia and SNNP. In other words, if HEP was non-existent there is a good chance that the trend in contraceptive use observed in these three regions was not going to be the same. The fact that Tigray differs from other regions where Agrarian-HEP is implemented and has similarities with the regions where Agrarian-HEP is not implemented needs explanation. One possibility is that Tigray region is paying much attention to the provision of maternal health care services particularly antenatal, delivery and postnatal care as it excels in these spheres compared to all other regions (see CSA and ICF, 20I2), and less attention to family planning. Further research is however needed to accept or reject this explanation.

Injectable is the most popular contraceptive method both in rural and urban Ethiopia

Injectable is by far the most commonly used contraceptive method by currently married women both in urban and rural Ethiopia. Uptake of injectable contraceptives has shown a marked increase in 2011 mainly due to the fact that HEWs provide injectable locally without necessarily visiting the health facilities at distant places (Prata, Gessessew, Cartwright \& Fraser, 20I I). In the past, injectable and implants were offered only by medical professionals in the clinics. Injectable is becoming more popular among contraceptive users in rural Ethiopia for three main reasons: firstly, the family planning programme in the country renews itself every two or three months depending on the type of dosage (Pörtner et al., 20I I); secondly, it is ideal for rural women without education, since the method does not require any user action except visiting a family planning clinic periodically; and thirdly, it does not focus the attention of their partner on the fact that they are using contraceptives (Ashraf et al., 2010). Most users believe that the injectable is an effective and safe form of contraception. The phenomenon of injectable becoming very popular in sub-Saharan Africa in recent times has been observed in many countries in sub-Saharan Africa (Adetunji, 20I I).
Education and work status are predictors of contraceptive use in rural but not in urban areas

The highest educational level and work status of women are consistently strong predictors of contraceptive use only in rural Ethiopia, while the effects are varying in urban areas. Education is understood to provide women with adequate information about birth control methods and the sources to obtain them. Better educated and working women have been found to accept birth control methods more readily than other women and abolish speculative rumours or negative perceptions of methods (Saleem \& Bobak, 2005; Tawiah, 1997). They also have wider access to IEC messages that are transmitted via the media discussing the advantages of small families. In urban areas where the effects of traditional norms and values are weakened, the rational choice of fewer children operating through informal discussion, the media and social networking could diminish the expected effects of education and work status on the adoption of contraceptive use.

\section{Evidence to reach out to the poor and disadvantaged women both in urban and rural Ethiopia}

Although the family planning programme of Ethiopia that was particularly controversial in the 1960s through 1980s is becoming a routine part of public health service delivery since the mid-1990s (Ahmed \& Mengistu, 2002), contraceptive uptake is higher among women living in economically medium and better off households compared to those living in low income households. This has implications to support and encourage women living in economically poor households both in rural and urban areas. They may require subsidised services so that their access to the contraceptive supplies would not be halted. Well organised and uninterrupted house-to-house visit services can also be helpful to increase contraceptive use by women earning their living with agricultural activities, and who have no access to the media. Providing effective and affordable contraceptive supplies within the reach of these groups of women will motivate them to spend more of their reproductive lives using family planning methods effectively and efficiently (Bongaarts et al., 2012). Attention must also be paid to the incon- 
sistent effects of religion on contraceptive use in Ethiopia. Whilst the progress towards adopting family planning methods among women following Protestant religion is encouraging, Muslims' recent trends of retreating from contraceptive use does not only require advocacy for limiting family size but also needs further investigation.

Commitment by the Ethiopian Government to the family planning programme is commendable but more devotion in allocating resources and promoting IEC messages is still required to achieve targets.

The reduction in family planning support from funding agencies has not affected the initiative of the Ethiopian Government to provide the means to regulate unwanted and unplanned pregnancies. Having recognised the significance of high-quality voluntary family planning programmes to promote socio-economic development and improve the well-being of mothers and children, the Ethiopian Government is running a nationwide family planning programme to reduce fertility rates (Ministry of Health, 2003). It has been noted that successful family planning programmes in Bangladesh, Indonesia, Nepal, and Sri Lanka that had unfavourable development conditions (for example, poor and largely uneducated communities) that resulted in rapid fertility declines were mainly due to government's commitment to run the programme effectively and efficiently (Bongaarts et al., 2012). In Ethiopia, as well, an increase in the contraceptive prevalence rate from 14 percent in 2005 to 28.6 percent in $20 \mathrm{II}$ and the decline of the total fertility rate from 5.4 in 2005 to 4.8 in $201 \mathrm{I}$ is due to the devotion of the Government to the family planning and related programmes. In spite of this, available evidence reveals that despite achieving measurable progress in the recent past and improving access to reproductive health services in rural areas, there is still an unmet need for family planning for at least a quarter of currently married women (CSA \& ICF, 20I2).

\section{Concluding remarks}

Unlike the majority of African countries, Ethiopia did not witness its family planning programme crumble when international funders changed their priorities to the detriment of family planning. The Ethiopian government has taken initiatives to include population issues into the school curricula, removed all rules and regulations that hamper women's access to contraceptive use and established a country-specific Health Extension Programme in 2003, of which the first phase (Agrarian-HEP) was launched in 2004. This study has attempted to identify correlates of contraceptive use in rural and urban Ethiopia and assessed indirectly the contribution of the HEP. The paper shows that the use of contraceptives has increased exponentially, particularly in the rural areas during the period 2005-20II. The multivariate analysis revealed that despite regional variation in the level of commitment to the implementation of the family planning package of the HEP in rural Ethiopia, the Agrarian-HEP has a marked contribution towards the use of contraception in three of the four regions along with the intervention through revising the school curricula and all laws dealing with the use and distribution of family planning services. Other African countries need to emulate such an initiative, but ensuring the implementation of the programme throughout the country at similar pace to avoid any negative implications from political perspectives.

\section{References}

Adetunji, J.A. (20II). Rising popularity of injectable contraceptives in sub-Saharan Africa. African Population Studies, 25(2): 587-604.

Ahmed, J. \& Mengistu, G. (2002). Evaluation of Program Options to Meet Unmet Need for Family Planning in Ethiopia. Calverton, Maryland USA: ORC Macro.

All Africa (20I2). Ethiopia: Speech by Ethiopia's Minister of Health at the London Summit on Family Planning. II July 2012.http://allafrica.com/ stories/201207 I I I 108.html assessed on 7

December 2012.

Alvergne, A., Gibson, M.A., Gurmu, E. \& Mace, R. (20II) Social Transmission and the Spread of Modern Contraception in Rural Ethiopia. PLoS ONE 6(7): e225I5. Doi:10.1371/ journal.pone.00225I 5 .

Argaw, H. (2007). The Health Extension Program: Summary of Concepts, Progress, Achievements and Challenges. Addis Ababa: WHO Country Office.

Ashraf, N., Field, E.\&Lee, J.(20I0). Household Bargaining and Excess Fertility: An ExperimentalStudy in Zambia. $h t t p: / /$ fmwww.bc.edu/ec-/SemF20 I I/Field.pdf accessed 
on 29 November 2012.

Bongaarts, J.(1997). Trends in Unwanted Childbearing in the Developing World. Studies in Family Planning, 28(4), 267-277.

Bongaarts, J. \&Sinding, S.W. (2009). A Response to Critics of Family Planning Programs. International Perspectives on Sexual and Reproductive Health, 35(I),39-44.

Bongaarts, J., Cleland J., Townsend , J.W., Bertrand, J.T. \& Das Gupta, M.(20I2). Family Planning Programs for the $21^{\text {st }}$ Century: Rationale and Design. New York: Population Council.

Casterline, J. B. \&Sinding,S. W.(2000). Unmet need for family planning in developing countries and implications for population policy."Population and Development Review, 26(4), 69I-723.

Central Statistical Authority (CSA) [Ethiopia] (1993). The 1990 National Family and Fertility Survey Report. Addis Ababa.

Central Statistical Authority (CSA) [Ethiopia] \& ORC Macro (200I). Ethiopia Demographic and Health Survey 2000. Addis Ababa, Ethiopia and Calverton, Maryland, USA: Central Statistical Authority and ORC Macro.

Central Statistical Agency (CSA) [Ethiopia] \& ORC Macro (2006). Ethiopia Demographic and Health Survey 2005. Addis Ababa, Ethiopia and Calverton, Maryland, USA: Central Statistical Agency and ORC Macro.

Central Statistical Agency (CSA) [Ethiopia] \& ICF International (20I2). Ethiopia Demographic and Health Survey 20I I. Addis Ababa, Ethiopia and Calverton, Maryland, USA: Central Statistical Agency and ICF International.

Centre for National Health Development in Ethiopia (CNHDE), Columbia University (20 I I a). Ethiopia Health Extension Program Evaluation Study 20052010, Volume I. Household Survey. Addis Ababa, Ethiopia: Centre for National Health Development in Ethiopia, Columbia University.

Centre for National Health Development in Ethiopia (CNHDE), Columbia University. (20I l b). Ethiopia Health Extension Program Evaluation Study 2007-2010, Volume II. Health Post and HEWs Performance Survey. Addis Ababa, Ethiopia: Centre for National Health Development in Ethiopia, Columbia University.

Cleland, J., Bernstein, S., Ezeh, A., Faundes, A., Glasier, A. \&Innis, J.. 2006. Family Planning: Unfinished Agenda. Lancet, 368, 1810-1827.

Ezra, M. and Gebreselassie, S. (1998). Handbook on Population and Family Life Education for Secondary School Teachers in Ethiopia. Addis Ababa: Institute for Curriculum Development and Research.

Family Guidance Association of Ethiopia (FGAE)
(2000). FGAE in perspective. Addis Ababa, Ethiopia: Family Guidance Association of Ethiopia. Giday, T., Asnake, M. \&Wilder, J. (2008). Ethiopia's Health Extension Programme: Pathfinder International's Support 2003-2007. Addis Ababa.

Hogan, M., Hogan, C., Foreman, K. J., Naghavi, M., Ahn, S.Y., Wang, M., Makela, S. M., Lopez, A. D., Lozano, R.\& Murray C. J.L. (2010). Maternal mortality for I8I countries, 1980-2008: A systematic analysis of progress towards Millennium Development Goals. The Lancet, 375(9726), 1609-1623.

Mayhew, S.M. and Adjei, S. (2004). Sexual and reproductive health: Challenges for prioritysetting in Ghana's health reforms. Health Policy and Planning, 19, 50-6I.

Ministry of Health [Ethiopia] (1996). Guidelines for Family Planning services in Ethiopia. Addis Ababa.

Ministry of Health [Ethiopia] (2003). Family Planning Extension Package. Addis Ababa.

Ministry of Health [Ethiopia] (2007). Health Extension Program in Ethiopia: Profile. Addis Ababa

Ministry of Health [Ethiopia]. (20I0). Health Sector Development Programme III: Annual Performance Report EFY 2002 (2009/10). Addis Ababa.

Ministry of Health [Ethiopia] \& World Health Organization (1999). An assessment of reproductive health need in Ethiopia. Expanding options in reproductive health. Geneva: WHO.

Population Census Commission [Ethiopia] (2008). Summary and Statistical Report of the 2007 Population and Housing Census: Population Size by Age and Sex. Addis Ababa.

Pörtner, C. C., Beegle, K. \& Christiaensen,L. (20I I). Family Planning and Fertility: Estimating Program Effects Using Cross-Sectional Data. Policy Research Working Paper 58I2. Washington, D.C.: The World Bank.

Prata, N., Gessessew, A., Cartwright,A. \& Fraser, A.(2011). Provision of injectable contraceptives in Ethiopia through community-based reproductive health agents. Bulletin of World Health Organization, 89(8), 556-564.

Saleem, S.\& Bobak,M. (2005). Women's autonomy, education and contraception use in Pakistan: a national study. Reproductive Health, 2(8) doi: 10.1 186/1 742-4755-2-8.

Singh, S., Darroch, J.E., Ashford, L.S. \& Vlassoff, M.(2009). Adding It Up: The Costs and Benefits of Investing in Family Planning and Maternal and Newborn Health. New York: Guttmacher Institute and United Nations Population Fund.

Stover, J. \& Ross, J. (2010). "How Increased Contraceptive Use Has Reduced Maternal Mortality." Maternal and Child Health Journal 
13(4): 687-95.

Tawiah, E.O. (1997). "Factors affecting

Contraceptive Use in Ghana." Journal of Biosocial Science29: |4|-|49.

Tawye, Yenehun, Jotie, F., Shigu, T. , Ngom,P. \&

Maggwa, N. (2005). The Potential Impact of

Community-Based Distribution Programmes on

Contraceptive Uptake in Resource-Poor Settings:
Evidence from Ethiopia.African Journal of Reproductive Health, 9(3), I5-26.

Transitional Government of Ethiopia (1993).

National Policy on Ethiopian Women. Addis Ababa.

United Nations (2006). Levels and Trends of Contraceptive Use as Assessed in 2002. New York: United Nations. 